\title{
CT Scan in the Prediction of Lymph Node Involvement in Ovarian Cancer - a Retrospective Analysis of a Tertiary Gyneco-Oncological Unit
}

\section{Einsatz von Computertomografie zur Vorhersage des Lymph- knotenbefalls beim Ovarialkarzinom - eine retrospektive Analyse einer Einrichtung der tertiären Gesundheitsvorsorge}

\section{(우(1) (옹}

Authors

Peter Widschwendter ${ }^{1}$, Alexandra Blersch ${ }^{1}$, Thomas W. P. Friedl ${ }^{1}$, Wolfgang Janni ${ }^{1}$, Christopher Kloth ${ }^{2}$, Amelie de Gregorio ${ }^{1}$, Niko de Gregorio ${ }^{1}$

\section{Affiliations \\ 1 Department of Gynecology and Obstetrics, University of Ulm, Ulm, Germany \\ 2 Department of Diagnostic and Interventional Radiology, University Hospital Ulm, Ulm, Germany}

Key words

ovarian cancer, imaging, lymph node involvement, CT scan, diagnostic performance

Schlüsselwörter

Ovarialkarzinom, Bildgebung, Lymphknotenmetastasen, Computertomografie, diagnostische Wertigkeit

$\begin{array}{ll}\text { received } & 28.8 .2019 \\ \text { revised } & 6.11 .2019 \\ \text { accepted } & 7.12 .2019\end{array}$

Bibliography

DOI https://doi.org/10.1055/a-1079-5158

published online 24.03.2020 | Geburtsh Frauenheilk 2020; 80: 518-525 @ Georg Thieme Verlag KG Stuttgart .

New York | ISSN 0016-5751

Correspondence

Peter Widschwendter

University Hospital Ulm, Department of Gynecology

and Obstetrics

Prittwitzstraße 43, 89075 Ulm, Germany

Peter.widschwendter@uniklinik-ulm.de

\section{ABSTRACT}

Background The prognostic value of lymph node removal in ovarian cancer varies depending on the tumor stage. While in the advanced stage the removal of clinically normal lymph nodes does not improve the prognosis, this is still unclear in the early stages. Evaluation of the lymph nodes based on preoperative imaging influences the surgical procedure.

Methods This retrospective analysis was performed by analyzing data from 114 patients with ovarian cancer, treated in our university hospital in the years 2000-2012. Diagnostic performance of imaging by computer tomography with respect to the correct prediction of lymph node status was analyzed in terms of sensitivity, specificity, positive predictive value and negative predictive value.

Results Imaging by computer tomography showed a rather limited diagnostic performance with regard to the detection of lymph node metastases in ovarian cancer, with a sensitivity of $40.7 \%$, a specificity of $89.1 \%$, a positive predictive value of $80.0 \%$, and a negative predictive value of $58.3 \%$. A separate analysis for pelvic and paraaortic lymph node involvement showed a better diagnostic performance of computer tomography for the detection of positive paraaortic lymph nodes $(41.2,93.1,84.0$, and $64.3 \%$ for sensitivity, specificity, positive predictive value and negative predictive value, respectively) as compared to the detection of positive pelvic lymph nodes (25.6, 91.8, 62.5, and 69.8\%).

Conclusion The preoperative prediction of lymph node status by computer tomography is limited. A decision for or against lymphadenectomy should not be made solely on the basis of this approach.

\section{ZUSAMMENFASSUNG}

Hintergrund Die prognostische Bedeutung einer Lymphknotendissektion beim Ovarialkarzinom variiert je nach Tumorstadium. Während im fortgeschrittenen Erkrankungsstadium die Entfernung von klinisch normalen Lymphknoten nicht zu einer Verbesserung der Prognose führt, ist noch nicht geklärt, ob dies auch im Frühstadium der Erkrankung zutrifft. Eine präoperative Lymphknotenevaluation mithilfe bildgebender Verfahren wirkt sich auf den nachfolgenden operativen Eingriff aus. 
Methoden Die Daten von 114 in unserer Universitätsklinik zwischen 2000 und 2012 behandelten Patientinnen mit Ovarialkarzinom wurden einer retrospektiven Analyse unterzogen. Die diagnostische Leistung der Computertomografie bei der korrekten Vorhersage des Lymphknotenstatus wurde in Bezug auf Sensitivität, Spezifität sowie positiven und negativen Vorhersagewert analysiert.

Ergebnisse Die Computertomografie hatte einen eher begrenzten diagnostischen Wert für die Entdeckung von Lymphknotenmetastasen beim Ovarialkarzinom: Die Sensitivität betrug $40,7 \%$, die Spezifität $89,1 \%$, der positive Vorhersagewert war $80,0 \%$ und der negative Vorhersagewert 58,3\%. Eine separate Analyse zur Bedeutung der Computertomografie bei der Entdeckung befallener pelviner und paraaortaler Lymphknoten stellte eine bessere diagnostische Leistung bei der Entdeckung von positiven paraaortalen Lymphknoten (41,2, $93,1,84,0$ bzw. 64,3\% für die Sensitivität, Spezifität und den positiven bzw. negativen Vorhersagewert) fest, verglichen mit der Auffindung von positiven pelvinen Lymphknoten (25,6, 91,8, 62,5 und 69,8\%).

Schlussfolgerung Die präoperative prognostische Aussage der Computertomografie bezüglich Lymphknotenstatus ist begrenzt. Die Entscheidung für oder gegen eine Lymphadenektomie sollte nicht nur auf dieser Grundlage getroffen werden.

\section{Prior Publication}

Presented at the congress of Deutsche Gesellschaft für Gynäkologie und Geburtshilfe (DGGG) in Berlin in November 2018.

\section{Introduction}

In 2012, over 230000 women worldwide were diagnosed with ovarian cancer, with Eastern and Central Europe having the highest incidence rates (11.4 and 6.0 per 100000 , respectively) [1]. The most important prognostic factors are the tumor stage and the removal of all visible tumor sites [2,3]. The 5-year survival rate through all stages is still below $50 \%$ despite continuous improvements, especially in systematic therapy [1]. Pelvic and paraaortic lymphadenectomy is considered a necessary part of staging surgery for early ovarian cancer (up to and including FIGO IIA) through its role in the correct assessment of the tumor stage and corresponding prognosis [4-7]. The incidence of pelvic and/or paraaortic lymph node metastases in FIGO stages I and II varies between 6.1 and $29.6 \%$ depending on the literature, with the highest incidence found in poorly differentiated and serous tumors [8]. Mucinous carcinomas or low grade serous carcinomas (LGSC), on the other hand, appear to have a very low risk for nodal spread $[9,10]$. In advanced ovarian cancer, several retrospective data showed that lymphadenectomy is beneficial for prognosis when a macroscopically tumor-free resection is achieved [11, 12]. Recently, however, the Lymphadenectomy In Ovarian Neoplasms (LION) study showed that in patients with advanced ovarian cancer (FIGO IIB - IV) and clinically (CT scan and intraoperative palpation) inconspicuous lymph nodes, omitting systematic lymphadenectomy did not worsen the prognosis, but operating time and peri- and postoperative morbidity were favorable for patients in the no lymphadenectomy group [13]. In addition, 30-day mortality was almost twice as high in the group where lymphadenectomy was performed. Interestingly, although the lymph nodes were described as normal in CT, metastases were histologically present in $55.7 \%$ of cases in the lymphadenectomy group.

However, when lymph nodes are enlarged and suspicious, lymphadenectomy up to the renal vein is still part of standard debulking surgery [2]. For the assessment of abdominal and retroperitoneal (nodal) tumor spread, computed tomography $(C T)$ is the standard imaging method in gynecological cancers [14-16] and is therefore crucial for optimal preoperative planning. However, there is limited data on the detection accuracy of lymph node metastases by $\mathrm{CT}$ scan in ovarian cancer.

In this retrospective single-centre study we therefore intended to evaluate the quality and predictive power of CT with regard to lymph node involvement in ovarian cancer on the basis of a patient cohort treated at our tertiary gyneco-oncological unit.

\section{Patients and Methods}

Out of 230 patients that presented with ovarian cancer at the Department of Gynecology and Obstetrics at our hospital between the years 2000 and 2012, 114 patients with complete data sets that received a primary surgery with the declared aim of complete cytoreduction and at least five removed lymph nodes were available for this analysis. The records from these patients with ovarian cancer that were treated with standard surgery (tumor debulking, pelvic and paraaortic lymphadenectomy up to the left renal vein) at our department were retrospectively analyzed. Therapeutic recommendations were based on current guidelines and made after patients were discussed with our radiologists on the basis of CT and possibly MRI images in our local tumor board. Until July 2006, the 2-slice model "TWIN RTS" and then the 16-slice model "Brilliance CT 16 Slice" both from Phillips were used for the computer tomography. A highly dose contrast-enhanced CT scan (kV 100 , effective $\mathrm{mAs} 228$, layer thickness $1 \mathrm{~mm}$ ) was performed before and 90 seconds after injection of a contrast medium. The CT examination was recommended when ovarian cancer was suspected and was performed a few weeks (2-4 weeks) prior to surgery. Lymph nodes were considered suspect if they were larger than $1 \mathrm{~cm}$ in their smallest diameter or if their shape deviated from the normal. Every CT scan was seen by at least two radiologists (advanced resident and senior radiologist). The staging laparotomy included at least removal of both adnexa, the uterus, omentum as well as the pelvic and paraaortic lymph nodes up to the left renal vein. In the case of tumor spread to other locations, the excision of these areas was carried out with the goal of complete cytoreduction. In cases where no complete cytoreduction could be achieved, systematic lymphadenectomy was omitted. The operation was performed exclusively by gynecological sur- 
geons with many years of oncological experience. Criteria for inclusion in the present analysis were the histological diagnosis of epithelial ovarian cancer and complete patient data (reports of indication, surgery, and histology). The FIGO classification used before the amendment, published in 2014 [17], was used. Patient records were extracted from our clinical documentation system SAP GUI (Graphical User Interface) and SAP ISH (Industry Solution Hospital; version 6.17 SP 18). Due to its retrospective character, no patient consent was required, while local ethics committee granted a positive vote to conduct this study (No. 228/17).

\section{Data Analysis}

Categorical data are described using absolute and relative frequencies, while the metric variables age (years), body mass index (BMI, $\mathrm{kg} / \mathrm{m}^{2}$ ) and the numbers of removed/positive lymph nodes are described using median and range. The diagnostic performance of the CT scan in terms of correct prediction of lymph node status was analyzed by calculating sensitivity, specificity, positive predictive value (PPV), negative predictive value (NPV), and percentage of correctly classified cases (accuracy). Statistical analyses were performed using IBM ${ }^{\circledR}$ SPSS ${ }^{\circledR}$ Statistics, version 24 (IBM Corp. Armonk, NY, USA). All statistical tests were two-sided, and $p$ values of less than 0.05 were considered significant.

\section{Results}

\section{Patient and tumor characteristics}

A total of 114 patients with lymphadenectomy (at least 5 removed lymph nodes) and complete CT diagnostics were included. Details on patient and tumor characteristics are given in $>$ Table 1. The median age was 58 years (range $29-85$ ) and median body mass index was $23.8 \mathrm{~kg} / \mathrm{m}^{2}\left(16.0-40.3 \mathrm{~kg} / \mathrm{m}^{2}\right)$. The most frequent FIGO stage was IIIC, which was observed in $43.9 \%$ of the patients. Any form of bowel surgery was performed in $19.3 \%$ of patients, a splenectomy in $3.5 \%$ and a stoma was necessary in $7.0 \%$ of cases. $65.8 \%$ of patients had no macroscopically residual tumors at the end of surgery, while the remaining $34.2 \%$ had residual tumors. Platinum-containing adjuvant chemotherapy was administered to $95.6 \%$ of patients.

Overall, a median number of 37 (range 5-76) lymph nodes was removed and 59 (51.8\%) patients had lymph node metastases with a median of 5 (1-48) positive lymph nodes. A median number of 24.5 pelvic lymph nodes (range 2-52) was removed in 112 patients (for two patients the institutional tumor board recommended paraaortic lymph node removal only), with at least one (median 3, range 1-26) positive pelvic lymph node diagnosed in $39(34.8 \%)$ patients. Paraaortic lymphadenectomy was performed in 109 patients with a median of $12(1-48)$ removed paraaortic lymph nodes. At least one positive paraaortic lymph node was detected in 51 (46.8\%) patients (median 2, range 1-22). Out of 65 patients with a FIGO stage III tumor, 47 (72.3\%) patients had a positive lymph node status, with $40(61.5 \%)$ patients showing at least one positive paraaortic node. A FIGO stage IV tumor was found in 14 patients, and 12 (85.7\%) of these patients had posi-
- Table 1 Baseline characteristics of patients with ovarian carcinoma and systematic lymphadenectomy $(n=114)$.

\begin{tabular}{|c|c|}
\hline Variable & \\
\hline \multicolumn{2}{|l|}{ Age (years) } \\
\hline - median & 58 \\
\hline - range & $29-85$ \\
\hline \multicolumn{2}{|c|}{ Body mass index $\left(\mathrm{kg} / \mathrm{m}^{2}\right)$} \\
\hline - median & 23.8 \\
\hline - range & $16.0-40.3$ \\
\hline - unknown (n) & 13 \\
\hline \multicolumn{2}{|l|}{ Staging laparoscopy } \\
\hline - no & $91(79.8 \%)$ \\
\hline - yes & $23(20.2 \%)$ \\
\hline \multicolumn{2}{|c|}{ Final tumor stage (FIGO) } \\
\hline - IA & $6(5.3 \%)$ \\
\hline. $\mathrm{IB}$ & $1(0.9 \%)$ \\
\hline. $\mathrm{IC}$ & $18(15.8 \%)$ \\
\hline - IIA & $4(3.5 \%)$ \\
\hline - IIB & $2(1.8 \%)$ \\
\hline - IIC & $4(3.5 \%)$ \\
\hline - IIIA & $10(8.8 \%)$ \\
\hline - IIIB & $5(4.4 \%)$ \\
\hline - IIIC & $50(43.9 \%)$ \\
\hline. $\mathrm{IV}$ & $14(12.3 \%)$ \\
\hline \multicolumn{2}{|c|}{ ASA (American Society of Anesthesiologists) } \\
\hline .1 & $5(4.4 \%)$ \\
\hline .2 & $58(50.9 \%)$ \\
\hline .3 & $37(32.5 \%)$ \\
\hline .4 & $1(0.9 \%)$ \\
\hline - unknown & $13(11.4 \%)$ \\
\hline \multicolumn{2}{|l|}{ Histological grading } \\
\hline - G1 & $11(9.6 \%)$ \\
\hline - G2 & $24(21.1 \%)$ \\
\hline . G3 & $67(58.8 \%)$ \\
\hline - unknown & $9(10.5 \%)$ \\
\hline \multicolumn{2}{|l|}{ Histological type } \\
\hline - serous & $65(57.0 \%)$ \\
\hline - mucinous & $4(3.5 \%)$ \\
\hline - clear cell & $8(7.0 \%)$ \\
\hline - endometrioid & $15(13.2 \%)$ \\
\hline - carcinosarcoma & $9(7.9 \%)$ \\
\hline - other & $13(11.4 \%)$ \\
\hline \multicolumn{2}{|l|}{ Ascites } \\
\hline - no & 32 (28.1\%) \\
\hline " yes & $72(63.2 \%)$ \\
\hline - unknown & $10(8.8 \%)$ \\
\hline
\end{tabular}

Continued next page 
- Table 1 Baseline characteristics of patients with ovarian carcinoma and systematic lymphadenectomy $(n=114)$. (Continued)

\begin{tabular}{|c|c|}
\hline Variable & \\
\hline \multicolumn{2}{|l|}{ Surgical procedure } \\
\hline - pelvic peritonectomy (partial/complete) & $62(54.4 \%)$ \\
\hline - peritonectomy diaphragm (partial/complete) & $14(12.3 \%)$ \\
\hline - intestine surgery & $22(19.3 \%)$ \\
\hline - splenectomy & $4(3.5 \%)$ \\
\hline \multicolumn{2}{|l|}{ Total number of lymph nodes removed } \\
\hline - median & 37.0 \\
\hline - range & $5-76$ \\
\hline \multicolumn{2}{|l|}{ All lymph nodes } \\
\hline - negative nodes & $55(48.2 \%)$ \\
\hline - at least one positive node & $59(51.8 \%)$ \\
\hline " (median, range) & $(5,1-48)$ \\
\hline \multicolumn{2}{|l|}{ Pelvic lymph nodes removed } \\
\hline - no & $2(1.8 \%)$ \\
\hline - yes & $112(98.2 \%)$ \\
\hline \multicolumn{2}{|l|}{ Number of pelvic lymph nodes removed $(n=112)$} \\
\hline - median & 24.5 \\
\hline - range & $2-52$ \\
\hline \multicolumn{2}{|l|}{ Pelvic lymph nodes $(n=112)$} \\
\hline - negative nodes & $73(65.2 \%)$ \\
\hline - at least one positive node & $39(34.8 \%)$ \\
\hline - (median, range) & $(3,1-26)$ \\
\hline \multicolumn{2}{|l|}{ Paraaortic lymph nodes removed } \\
\hline " no & $5(4.4 \%)$ \\
\hline - yes & $109(95.6 \%)$ \\
\hline \multicolumn{2}{|l|}{$\begin{array}{l}\text { Number of paraaortic lymph nodes removed } \\
(n=109)\end{array}$} \\
\hline - median & 12 \\
\hline - range & $1-48$ \\
\hline \multicolumn{2}{|l|}{ Paraaortic lymph nodes $(n=109)$} \\
\hline - negative nodes & $58(53.2 \%)$ \\
\hline - at least one positive node & $51(46.8 \%)$ \\
\hline - (median, range) & $(2,1-22)$ \\
\hline \multicolumn{2}{|l|}{ Adjuvant chemotherapy (platinum based) } \\
\hline - no & $4(3.5 \%)$ \\
\hline - yes & $109(95.6 \%)$ \\
\hline - unknown & $1(0.9 \%)$ \\
\hline \multicolumn{2}{|l|}{ Residual tumor } \\
\hline " no & $75(65.8 \%)$ \\
\hline - yes & $39(34.2 \%)$ \\
\hline
\end{tabular}

tive nodes; 11 (78.6\%) patients had at least one metastasis in paraaortic nodes.

\section{CT scan and overall lymph node involvement}

49 out of 55 patients with histologically confirmed negative lymph node status had also unsuspicious nodes in the CT scan, while 24 out of 59 patients with confirmed lymph node metastases also showed suspected nodes in the CT scan. Thus, lymph node status was predicted correctly in $73(64.0 \%)$ of the 114 patients. Diagnostic key values were a sensitivity of $40.7 \%$, a specificity of $89.1 \%$, a PPV of $80.0 \%$ and a NPV of $58.3 \%$ ( Fig. 1).

\section{CT scan and pelvic lymph node involvement}

Based on the CT scan, suspect pelvic lymph nodes were described in 10 of 39 patients with histologically confirmed positive pelvic nodes. In 67 of 73 patients with histologically confirmed negative pelvic lymph node status the CT scan also showed unsuspicious nodes. Correct prediction of pelvic lymph node status by CT scan was thus achieved in 77 (68.8\%) of the 112 patients that received a pelvic lymphadenectomy. The corresponding values for sensitivity, specificity, PPV and NPV were 25.6, 91.8, 62.5, and 69.8\%, respectively ( $\bullet$ Fig. 1 ).

\section{CT scan and paraaortic lymph node involvement}

Paraaortic lymph nodes were described as suspect based on the CT scan in 21 of 51 patients with histologically confirmed positive paraaortic nodes. On the other hand, in 54 of 58 patients with histologically confirmed negative paraaortic lymph node status, paraaortic nodes were also considered unsuspicious nodes based on the CT scan. Taken together, paraaortic lymph node status was correctly predicted by CR scan in 75 (68.8\%) of 109 patients with a paraaortic lymphadenectomy. Sensitivity was $41.2 \%$, specificity 93.1\%, PPV $84.0 \%$ and negative predictive value $64.3 \%$ ( Fig. 1).

\section{Subgroup analysis of patients with systematic lymph node dissection only}

Given that the evaluation of the diagnostic performance of CT scans with regard to the detection of lymph node involvement might be severely limited in cases with only few removed lymph nodes, we performed an additional subgroup analysis incorporating only patients with a systematic lymph node dissection as defined by at least 15 removed pelvic lymph nodes and 10 removed paraaortic lymph nodes. In the 57 patients included in this subgroup analysis, median numbers of pelvic and paraaortic lymph nodes removed were 29 (range 15-52) and 17 (range 10-48), respectively. 28 (49.1\%) patients had histologically confirmed positive nodes (range 1-48); 3 (5.3\%) patients had positive pelvic nodes only, $17(29.8 \%)$ had both positive pelvic and paraaortic nodes, and $8(14.0 \%)$ had positive paraaortic lymph nodes without evidence of positive pelvic nodes.

Overall, the diagnostic performance of CT scans did not change substantially when only patients with a systematic lymph node dissection were analyzed ( $\mathbf{F i g . 2}$ ). Overall, lymph node status was predicted correctly in 39 (68.2\%) of the 57 patients, with diagnostic key values being 53.6, 82.2, 75.0 and 64.9\% for sensitivity, specificity, PPV and NPV, respectively. With regard to the prediction of pelvic lymph node involvement, 40 (68.4\%) of patients were correctly classified, and the values for sensitivity, specificity, PPV and NPV were 30.0, 89.2, 60.0 and 70.2\%, respectively. Paraaortic lymph node involvement was correctly predicted in 42 (73.7\%) patients; sensitivity, specificity, PPV and NPV were 56.0, $87.5,77.8$ and $71.8 \%$, respectively. 


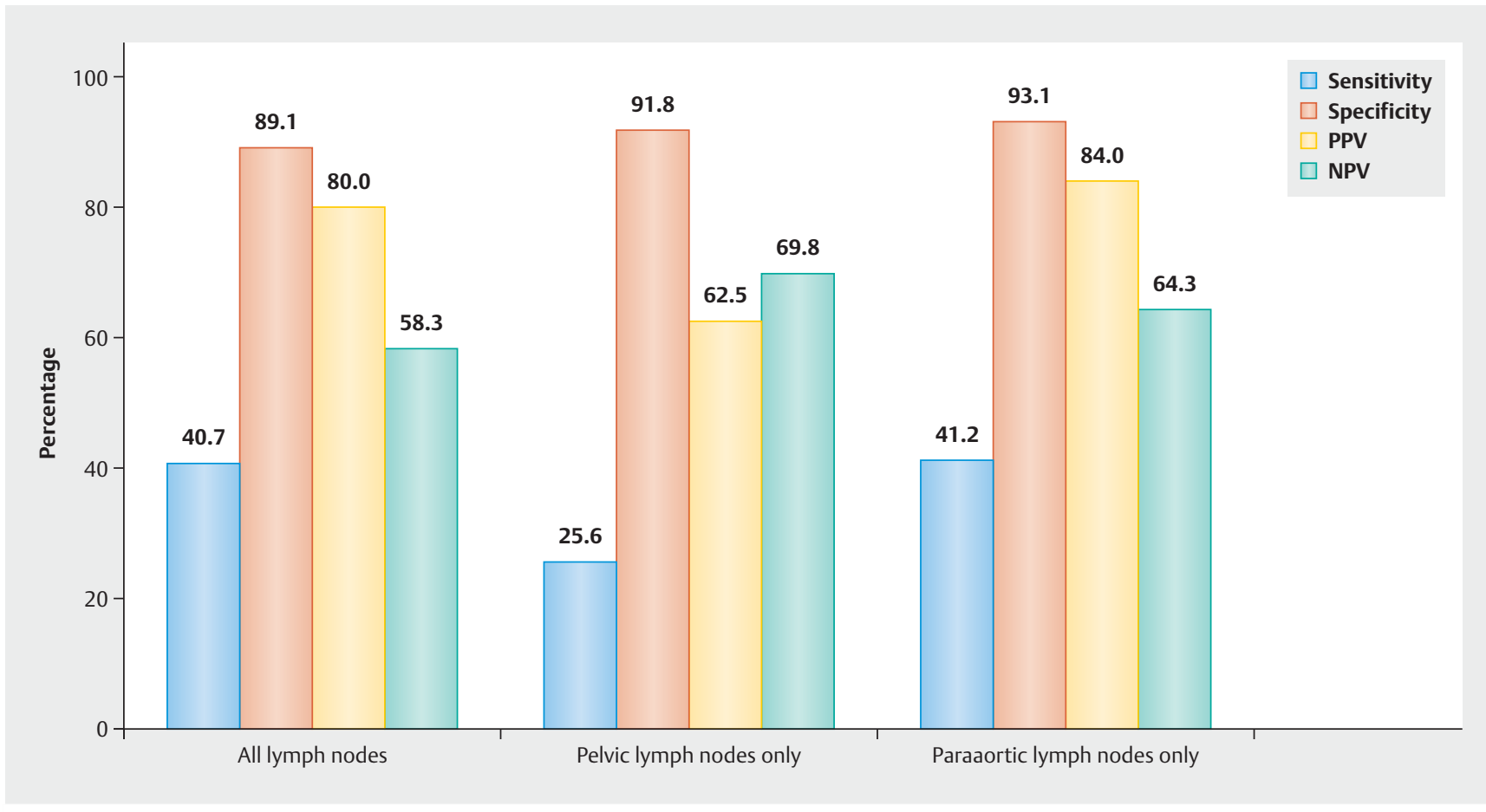

- Fig. 1 Diagnostic performance in terms of sensitivity, specificity, positive predictive value (PPV) and negative predictive value (NPV) of CT scans with regard to the correct prediction of lymph node status (positive vs. negative) for all lymph nodes, pelvic lymph nodes only and paraaortic lymph nodes only. Full patient cohort $(n=114)$.

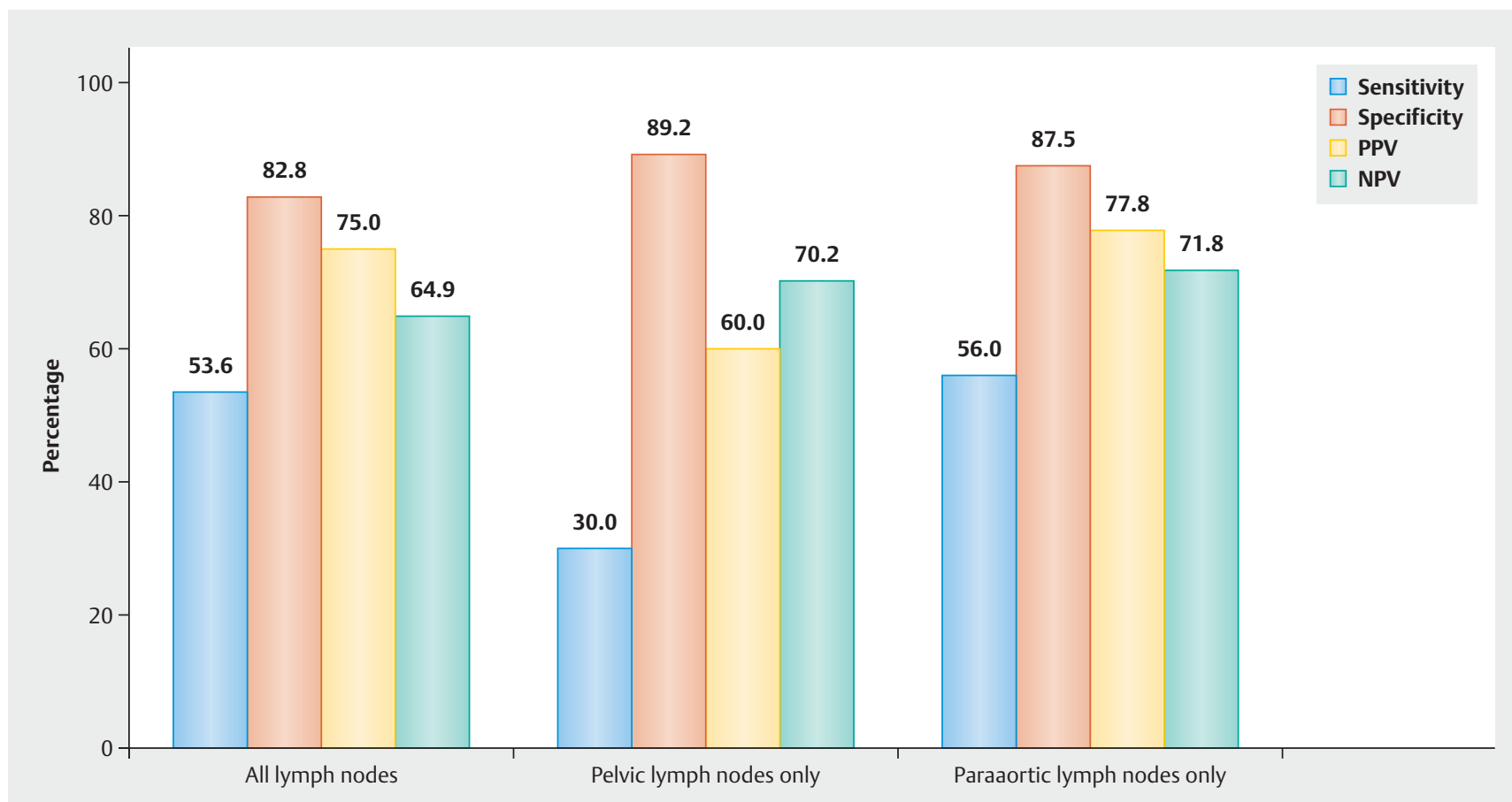

- Fig. 2 Diagnostic performance in terms of sensitivity, specificity, positive predictive value (PPV) and negative predictive value (NPV) of CT scans with regard to the correct prediction of lymph node status (positive vs. negative) for all lymph nodes, pelvic lymph nodes only and paraaortic lymph nodes only. Only patients with a systematic lymph node dissection as defined by removal of at least 15 pelvic and 10 paraaortic lymph nodes $(n=57)$. 


\section{Discussion}

In this retrospective study, we found that CT has a rather low sensitivity of $40.7 \%$ but a considerably higher specificity of $89.1 \%$ with regard to the detection of lymph node metastases (pelvic and/or paraaortic) in ovarian cancer. A separate analysis for pelvic and paraaortic lymph node involvement showed a better diagnostic performance of CT for the detection of positive paraaortic lymph nodes (sensitivity and specificity of 41.2 and $93.1 \%$, respectively), as compared to the detection of positive pelvic lymph nodes (sensitivity and specificity of 25.6 and $91.8 \%$, respectively).

Interestingly, the diagnostic performance of CT scans with respect to the detection of lymph node involvement did not improve that much compared to the full patient cohort when only patients with a systematic lymph node dissection (at least 15 removed pelvic and 10 removed paraaortic nodes) were analyzed. Sensitivity and negative predictive values increased somewhat, while we observed a corresponding slight decrease of specificity and positive predictive value. Thus, our results indicate that the diagnostic performance of CT scans with respect to the detection of lymph node involvement in ovarian cancer remains limited even if only patients with a large number of removed lymph nodes are considered.

Compared to other gynecological tumors such as cervical carcinoma, the lymph node status seems to have a limited prognostic relevance in ovarian cancer, at least in the advanced stage ( $\geq$ FIGO IIB). In the prospective randomized multicenter LION study [13], in which patients with advanced ovarian carcinoma ( $\geq$ IIB), clinically unsuspicious lymph nodes and optimal debulking surgery were randomized for complete pelvic and paraaortic lymphadenectomy versus no removal of the lymph nodes, there was no difference in overall survival (HR 1.06; 95\% Cl, 0.83-1.34; $\mathrm{p}=0.65)$ and disease-free survival (HR 1.11, 95\% Cl, 0.92-1.34; $p=0.29$ ). However, the key point is that $55.7 \%$ of patients in the lymphadenectomy group had lymph node metastases, although they had been described as normal in CT scan.

In early ovarian carcinoma on the other hand, retroperitoneal exploration of the lymph nodes is of diagnostic value, as reflected by a change in adjuvant therapy once lymph node metastases are detected, but the therapeutic benefit of lymphadenectomy per se remains unclear $[18,19]$. The incidence of lymph node metastases in stages FIGO I and II is 14.2\% (range 6.1-29.6\%) and is strongly associated with histological subtype and higher grading $[8,20]$. In a large retrospective evaluation of 762 patients with epithelial ovarian carcinoma (EOC, FIGO I-IV), Heitz and colleagues showed that a positive nodal status even in an adjusted multivariable Cox regression analysis was significantly associated with poor overall survival (HR 1.52, 95\% Cl 1.1-2.1; p = 0.014) [10]. In another analysis of more than 6000 patients with FIGO stage I, Chan and collegues could even demonstrate a clear survival advantage for patients with systematic lymphadenectomy independent of other prognostic factors [4]. However, other studies could not find a survival advantage of lymphadenectomy over no lymphadenectomy or sampling of a few lymph nodes confined to the pelvis in ovarian cancer [21,22]. Nevertheless, a systematic lymphadenectomy is indicated for macroscopically abnormal and especially for bulky nodes - independent of FIGO stage [23] or histology [24].
Preoperative knowledge of the lymph node status is therefore of enormous importance for therapy planning. The lymph drainage of the ovaries runs primarily via the infundibulopelvic ligament into the paraaortic and paracaval region [25] with increasing incidence of lymph node metastases at higher FIGO stages [26]. However, also pelvic lymph node metastases are common in ovarian cancer, especially in higher tumor stages [27]. Preoperative cross-sectional imaging should always be performed if ovarian carcinoma is suspected; in this case CT is most frequently used as a tool to evaluate intraabdominal and retroperitoneal (lymph node) tumor spread [2].

In a review, Rutten et al. examined a total of 11 studies that have established prediction models for the probability of complete cytoreduction using the preoperative CT scan [28]. In five of these studies which included patients with ovarian carcinoma of stages FIGO III and IV, the infrarenal lymph node status was explicitly included in the evaluation [14,29-32]. In the retrospective analysis of 41 patients conducted by Bristow, a sensitivity for infrarenal paraaortic lymph nodes (pathological from $\geq 2 \mathrm{~cm}$ ) of only $14.3 \%$ was found, showing the limited value of this method in the prediction of correct lymph node status. However, our study revealed a considerably higher sensitivity rate $(41.2 \%)$ for the detection of paraaortic lymph node metastases, which was also higher compared to the sensitivity for the detection of pelvic lymph nodes (25.6\%).

In a large prospective study, conducted by Ferrandina and colleagues, 195 patients with advanced ovarian carcinoma were examined to determine which constellation of radiological (CT scan) and clinical parameters could predict optimal cytoreduction. The evaluation of infrarenal paraaortic lymph nodes (pathological from $\geq 2 \mathrm{~cm}$ ) also had significant predictive power with an accuracy of $81.9 \%$ (specificity $91.8 \%$, PPV $50.0 \%$, NPV $86.6 \%$ ) [14]. These data are essentially in line with our results with regard to the paraaortic region, showing an accuracy of $68.8 \%$ with a sensitivity of $41.2 \%$.

Nevertheless, the main question in the studies listed in the review by Rutten was not whether lymph nodes that are diagnosed as positive in CT also show histologically confirmed metastases although this had to be assumed by the size of more than $2 \mathrm{~cm}$ as well -, but rather whether or not enlarged lymph nodes represent a limiting parameter for optimal cytoreduction. The relevant parameter whether lymph nodes are considered benign or malignant is their size, and a size of $10 \mathrm{~mm}$ or more in short-axis diameter is considered pathological [33]. In this context, the results of a prospective randomized trial show once more the limitations of the method: Patients with advanced ovarian cancer were randomized either to systematic lymphadenectomy or only removal of socalled bulky nodes. In the lymphadenectomy group, more lymph node metastases were confirmed $(70 \%)$ due to the significantly larger number of nodes removed. Nevertheless, in the bulky nodes group only $42 \%$ of the lymph nodes were positive, although these nodes were actually classified as pathologic due to their size [34]. The LION study, however, did not describe to what extent quality criteria were also relevant for the selection of participating radiologists.

These results indicate that diagnosing the pathology based on the size of the lymph nodes does not seem to be sufficiently safe 
for decisions of such a morbidity-prone surgery as lymphadenectomy. Looking at our data, the PPV for the detection of pelvic and paraaortic lymph node metastases is 62.5 and $84.0 \%$, respectively. It should be explained to the patients in the context of the preoperative patient information - especially in cases with advanced carcinomas - that in about $30 \%$ of the patients a lymph node removal possibly represents an overtreatment with a corresponding increase in morbidity.

In early ovarian carcinomas (FIGO I-IIA), the rate of lymph node metastases is between 11 and $53 \%$, with paraaortic positive nodes being detected significantly more frequently than pelvic positive nodes [7]. Especially low grade ovarian carcinomas seem to have a high potential for lymphogenic spread [10,22]. A prospective randomized study could not prove a significant difference in progression-free and overall survival between patients with systematic lymphadenectomy compared with lymph nodes sampling in early ovarian cancer (confined to the pelvis), probably due to the lack of statistical power [21]. Retrospective analyses, however, showed that lymphadenectomy was an independent prognostic factor for better survival, even in multivariate analyses $[4,35]$. Nevertheless, until the data from the prospective LION study were published, lymphadenectomy in advanced ovarian cancer was also a standard component of surgical therapy due to survival advantages reported in retrospective studies. Such a paradigm shift as implemented after the LION study also shows the problematic of relying on retrospective studies only.

If macroscopic, static imaging has such a low accuracy, it makes sense to evaluate dynamic examination techniques for their diagnostic accuracy [36]. Dynamic contrast-enhanced (DCE) Magnetic Resonance Imaging (MRI) and Diffusion Weighted Imaging (DWI) MRI can dynamically visualize changes in the microvasculature - e.g. during tumor angiogenesis - by repetitive imaging during gadolinium contrast agent application [37]. In a pooled meta-analysis, Liu and colleagues were able to demonstrate that DWI-MRI has similar accuracy with regard to the detection of lymph node metastases to fluorodeoxyglucose positron emission tomography (area under the curve 0.9 and 0.92 , respectively). However, MRI has a comparatively low specificity of $83 \%$ (Fluorodeoxyglucose positron emission tomography 98\%), so that it is only recommended as a supplementary method [38]. Nevertheless, CT is the most frequently available imaging technique in this field, while PET-CT and MRI are not available across the board. PET-CT and PET-MRI in particular require further evaluation in the diagnosis of ovarian cancer [39].

Limitations of our study are the relatively small sample size and the retrospective character.

\section{Conclusion}

The accuracy of CT-scan in detecting lymph node metastasis in ovarian cancer is limited. Especially in advanced stages, CT findings with suspected metastatic lymph nodes should be critically re-evaluated preoperatively. In case of doubt, we would recommend to remove only the region of lymph nodes described as suspect in CT instead of a systematic lymphadenectomy.

\section{Acknowledgements}

We would thank Alexandra Blersch, Amelie de Gregorio and Nikolaus de Gregorio for conception, study design and data collection, Christopher Kloth and Thomas Friedl for data analysis and manuscript writing and editing and Wolfgang Janni for conception and editing the manuscript.

\section{Conflict of Interest}

The authors declare that they have no conflict of interest.

\section{References}

[1] Reid BM, Permuth JB, Sellers TA. Epidemiology of ovarian cancer: a review. Cancer Biol Med 2017; 14: 9-32. Online: http://www.ncbi.nlm. nih.gov/pubmed/28443200

[2] Colombo N, Sessa C, du Bois A et al.; ESMO-ESGO Ovarian Cancer Consensus Conference Working Group. ESMO-ESGO consensus conference recommendations on ovarian cancer: pathology and molecular biology, early and advanced stages, borderline tumours and recurrent disease. Int J Gynecol Cancer 2019; 29: 728-760. Online: http://www.ncbi.nlm. nih.gov/pubmed/31048403

[3] Bristow RE, Tomacruz RS, Armstrong DK et al. Survival Effect of Maximal Cytoreductive Surgery for Advanced Ovarian Carcinoma During the Platinum Era: A Meta-Analysis. J Clin Oncol 2002; 20: 1248-1259. Online: http://www.ncbi.nlm.nih.gov/pubmed/11870167

[4] Chan JK, Munro EG, Cheung MK et al. Association of Lymphadenectomy and Survival in Stage I Ovarian Cancer Patients. Obstet Gynecol 2007; 109: 12-19. Online: http://insights.ovid.com/crossref?an=00006250200701000-00004

[5] Kleppe M, van der Aa MA, Van Gorp T et al. The impact of lymph node dissection and adjuvant chemotherapy on survival: A nationwide cohort study of patients with clinical early-stage ovarian cancer. Eur J Cancer 2016; 66: 83-90. Online: https://linkinghub.elsevier.com/retrieve/pii/ S0959804916323176

[6] Morice P, Joulie F, Camatte $S$ et al. Lymph node involvement in epithelial ovarian cancer: analysis of 276 pelvic and paraaortic lymphadenectomies and surgical implications. J Am Coll Surg 2003; 197: 198-205. Online: http://www.ncbi.nlm.nih.gov/pubmed/12892797

[7] Powless CA, Aletti GD, Bakkum-Gamez JN et al. Risk factors for lymph node metastasis in apparent early-stage epithelial ovarian cancer: Implications for surgical staging. Gynecol Oncol 2011; 122: 536-540. Online: http://www.ncbi.nlm.nih.gov/pubmed/21636114

[8] Kleppe M, Wang T, Van Gorp T et al. Lymph node metastasis in stages I and II ovarian cancer: A review. Gynecol Oncol 2011; 123: 610-614. Online: http://www.gynecologiconcology-online.net/article/S00908258(11)00783-9/pdf

[9] Muyldermans K, Moerman P, Amant F et al. Primary invasive mucinous ovarian carcinoma of the intestinal type: importance of the expansile versus infiltrative type in predicting recurrence and lymph node metastases. Eur J Cancer 2013; 49: 1600-1608. Online: https://linkinghub. elsevier.com/retrieve/pii/S0959804912009616

[10] Heitz F, Harter P, Ataseven B et al. Stage- and Histologic Subtype-Dependent Frequency of Lymph Node Metastases in Patients with Epithelial Ovarian Cancer Undergoing Systematic Pelvic and Paraaortic Lymphadenectomy. Ann Surg Oncol 2018; 25: 2053-2059. Online: https://link. springer.com/content/pdf/10.1245\%2Fs10434-018-6412-y.pdf

[11] du Bois A, Reuss A, Harter P et al.; Arbeitsgemeinschaft Gynaekologische Onkologie Studiengruppe Ovarialkarzinom; Groupe d'Investigateurs Nationaux pour l'Etude des Cancers Ovariens. Potential Role of Lymphadenectomy in Advanced Ovarian Cancer: A Combined Exploratory Analysis of Three Prospectively Randomized Phase III Multicenter Trials. J Clin 
Oncol 2010; 28: 1733-1739. Online: http://www.ncbi.nlm.nih.gov/ pubmed/20194855

[12] Ataseven B, Grimm C, Harter P et al. Prognostic value of lymph node ratio in patients with advanced epithelial ovarian cancer. Gynecol Oncol 2014; 135: 435-440. Online: http://www.ncbi.nlm.nih.gov/pubmed/ 25312398

[13] Harter P, Sehouli J, Lorusso D et al. A Randomized Trial of Lymphadenectomy in Patients with Advanced Ovarian Neoplasms. N Engl J Med 2019; 380: 822-832. Online: http://www.ncbi.nlm.nih.gov/pubmed/ 30811909

[14] Ferrandina G, Sallustio G, Fagotti A et al. Role of CT scan-based and clinical evaluation in the preoperative prediction of optimal cytoreduction in advanced ovarian cancer: a prospective trial. $\mathrm{Br}$ J Cancer 2009; 101: 1066-1073. Online: http://www.ncbi.nlm.nih.gov/pubmed/19738608

[15] Suidan RS, Ramirez PT, Sarasohn DM et al. A multicenter prospective trial evaluating the ability of preoperative computed tomography scan and serum CA-125 to predict suboptimal cytoreduction at primary debulking surgery for advanced ovarian, fallopian tube, and peritoneal cancer. Gynecol Oncol 2014; 134: 455-461. Online: http://www.ncbi.nlm.nih. gov/pubmed/25019568

[16] Gemer O, Gdalevich M, Ravid M et al. A multicenter validation of computerized tomography models as predictors of non- optimal primary cytoreduction of advanced epithelial ovarian cancer. Eur J Surg Oncol 2009; 35: 1109-1112. Online: http://www.ncbi.nlm.nih.gov/pubmed/ 19329270

[17] Prat J; FIGO Committee on Gynecologic Oncology. FIGO's staging classification for cancer of the ovary, fallopian tube, and peritoneum: abridged republication. J Gynecol Oncol 2015; 26: 87-89. Online: http://www.ncbi.nlm.nih.gov/pubmed/25872889

[18] Camara O, Sehouli J. Controversies in the management of ovarian cancer-pros and cons for lymph node dissection in ovarian cancer. Anticancer Res 2009; 29: 2837-2843. Online: http://www.ncbi.nlm.nih. gov/pubmed/19596971

[19] Trimbos B, Timmers P, Pecorelli S et al. Surgical Staging and Treatment of Early Ovarian Cancer: Long-term Analysis From a Randomized Trial. J Natl Cancer Inst 2010; 102: 982-987. Online: http://www.ncbi.nlm.nih.gov/ pubmed/20445161

[20] Erdem B, Yüksel IT, Peker N et al. Evaluation of Factors Affecting Lymph Node Metastasis in Clinical Stage I-II Epithelial Ovarian Cancer. Oncol Res Treat 2018; 41: 444-448. Online: http://www.ncbi.nlm.nih.gov/ pubmed/29975960

[21] Maggioni A, Benedetti Panici P, Dell'Anna T et al. Randomised study of systematic lymphadenectomy in patients with epithelial ovarian cancer macroscopically confined to the pelvis. $\mathrm{Br}$ J Cancer 2006; 95: 699-704. Online: http://www.nature.com/articles/6603323

[22] Minig L, Heitz F, Cibula D et al. Patterns of Lymph Node Metastases in Apparent Stage I Low-Grade Epithelial Ovarian Cancer: A Multicenter Study. Ann Surg Oncol 2017; 24: 2720-2726. Online: http://link. springer.com/10.1245/s10434-017-5919-y

[23] Hacker NF, Valmadre S, Robertson G. Management of retroperitoneal lymph nodes in advanced ovarian cancer. Int J Gynecol Cancer 2008; 18: 7-10. Online: http://www.ncbi.nlm.nih.gov/pubmed/18336392

[24] Ricciardi E, Baert T, Ataseven B et al. Low-grade Serous Ovarian Carcinoma. Geburtsh Frauenheilk 2018; 78: 972-976. Online: http://www.ncbi. nlm.nih.gov/pubmed/30364401

[25] Plentl AA, Friedman EA. Lymphatic system of the female genitalia. The morphologic basis of oncologic diagnosis and therapy. Major Probl Obstet Gynecol 1971; 2: 1-223. Online: http://www.ncbi.nlm.nih.gov/ pubmed/5162136
[26] Scarabelli C, Gallo A, Zarrelli A et al. Systematic Pelvic and Para-aortic Lymphadenectomy during Cytoreductive Surgery in Advanced Ovarian Cancer: Potential Benefit on Survival. Gynecol Oncol 1995; 56: 328337. Online: http://www.ncbi.nlm.nih.gov/pubmed/7705665

[27] Berek JS. Lymph Node-Positive Stage IIIC Ovarian Cancer: A Separate Entity? Int J Gynecol Cancer 2009; 19: S18. Online: http://www.ncbi.nlm. nih.gov/pubmed/19955908

[28] Rutten M], van de Vrie R, Bruining A et al. Predicting Surgical Outcome in Patients With International Federation of Gynecology and Obstetrics Stage III or IV Ovarian Cancer Using Computed Tomography. Int J Gynecol Cancer 2015; 25: 407-415. Online: https://ijgc.bmj.com/ lookup/doi/10.1097/IGC.0000000000000368

[29] Bristow RE, Duska LR, Lambrou NC et al. A model for predicting surgical outcome in patients with advanced ovarian carcinoma using computed tomography. Cancer 2000; 89: 1532-1540. Online: http://www.ncbi. nlm.nih.gov/pubmed/11013368

[30] Dowdy SC, Mullany SA, Brandt KR et al. The utility of computed tomography scans in predicting suboptimal cytoreductive surgery in women with advanced ovarian carcinoma. Cancer 2004; 101: 346-352. Online: http://www.ncbi.nlm.nih.gov/pubmed/15241833

[31] Axtell $A E$, Lee $M H$, Bristow RE et al. Multi-institutional reciprocal validation study of computed tomography predictors of suboptimal primary cytoreduction in patients with advanced ovarian cancer. J Clin Oncol 2007; 25: 384-389. Online: http://ascopubs.org/doi/10.1200/ JCO.2006.07.7800

[32] Stashwick C, Post MD, Arruda JS et al. Surgical Risk Score Predicts Suboptimal Debulking or a Major Perioperative Complication in Patients With Advanced Epithelial Ovarian, Fallopian Tube, or Primary Peritoneal Cancer. Int J Gynecol Cancer 2011; 21: 1422-1427. Online: https://ijgc. bmj.com/lookup/doi/10.1097/IGC.0b013e31822c7704

[33] Paño B, Sebastià C, Ripoll E et al. Pathways of lymphatic spread in gynecologic malignancies. Radiographics 2015; 35: 916-945. Online: http:// pubs.rsna.org/doi/10.1148/rg.2015140086

[34] Panici PB, Maggioni A, Hacker N et al. Systematic aortic and pelvic lymphadenectomy versus resection of bulky nodes only in optimally debulked advanced ovarian cancer: a randomized clinical trial. J Natl Cancer Inst 2005; 97: 560-566. Online: http://academic.oup.com/jnci/article/ 97/8/560/2544193/Systematic-Aortic-and-Pelvic-Lymphadenectomy

[35] Trimbos B, Timmers P, Pecorelli S et al. Surgical staging and treatment of early ovarian cancer: Long-term analysis from a randomized trial. J Natl Cancer Inst 2010; 102: 982-987

[36] Laasik M, Kemppainen J, Auranen A et al. Behavior of FDG-avid supradiaphragmatic lymph nodes in PET/CT throughout primary therapy in advanced serous epithelial ovarian cancer: a prospective study. Cancer Imaging 2019; 19: 27. Online: https://www.ncbi.nlm.nih.gov/pmc| articles/PMC6542004/

[37] Vandecaveye V, Dresen R, De Keyzer F. Novel imaging techniques in gynaecological cancer. Curr Opin Oncol 2017; 29: 335-342. Online: http:// www.ncbi.nlm.nih.gov/pubmed/28594645

[38] Liu B, Gao S, Li S. A Comprehensive Comparison of CT, MRI, Positron Emission Tomography or Positron Emission Tomography/CT, and Diffusion Weighted Imaging-MRI for Detecting the Lymph Nodes Metastases in Patients with Cervical Cancer: A Meta-Analysis Based on 67 Studies. Gynecol Obstet Invest 2017; 82: 209-222. Online: http://www.ncbi. nlm.nih.gov/pubmed/28183074

[39] Khiewvan B, Torigian DA, Emamzadehfard S et al. An update on the role of PET/CT and PET/MRI in ovarian cancer. Eur J Nucl Med Mol Imaging 2017; 44: 1079-1091. Online: http://www.ncbi.nlm.nih.gov/pubmed/ 28180966 